\title{
Coordination Relationship Between Green Innovation Efficiency and Environmental Protection: Evidence From the Yangtze River Economic Belt
}

\author{
Na Hou, Zhi Zeng, Qianying Zhu, Dahong Zhang and Wenwen Liu $\dagger$ \\ School of Economics and Management, Beijing Forestry University, Beijing 100083, China \\ †Corresponding author: Wenwen Liu: wenwensummer@163.com
}

Nat. Env. \& Poll. Tech.

Website: www.neptjournal.com

Received: 27-02-2021

Revised: 13-04-2021

Accepted: 25-04-2021

\section{Key Words:}

Green innovation efficiency Environmental protection

Yangtze river economic belt Ecological environment

\begin{abstract}
Green innovation plays an important role in coordinating the relationship between ecological environment and economic development and has become a new driving force for the development of a resource-saving and environment-friendly economy. To explore the effects and logic of innovation efficiency and environmental protection, using the inter-provincial (city) panel data of the Yangtze River Economic Belt from 2007 to 2017 in China, the green innovation efficiency and environmental protection level of the upper, middle, and lower reaches of the Yangtze River Economic Belt were analyzed. Results show that the overall environmental protection level of the Yangtze River Economic Belt is on the rise. From a regional perspective, the environmental protection level in the upper reaches is the highest, which is greater than the overall level of the Yangtze River Economic Belt, followed by the lower and middle reaches, which are less than the overall level of the Yangtze River Economic Belt. The efficiency of green innovation has promoted the overall environmental protection level of the Yangtze River Economic Belt, inhibited the environmental protection level in the downstream areas, promoted the environmental protection level in the upstream areas, and has no obvious impact on the environmental protection level in the middle reaches. Further mechanism analysis shows that the possible transmission path of green innovation efficiency to environmental protection is as follows: green innovation efficiency promotes the environmental protection level by improving the ecological environmental efficiency. The robustness of the above conclusion is tested, and it has good robustness. The research conclusions of this study provide reliable empirical evidence and policy enlightenment for the development and optimization of green innovation efficiency and the realization of green innovation efficiency driving environmental protection.
\end{abstract}

\section{INTRODUCTION}

Green innovation efficiency is the key factor to maintain economic growth. After the economic development of developing countries has gone through the barbaric stage of economic growth in exchange for resources and the environment, ecological problems have become increasingly exposed and have severely limited the quality of economic growth and the quality of life of people. The importance of dynamic reconciliation of contradictions among economy, society, and ecology has gradually become prominent. The manner by which to rationally and objectively measure the relationship among economic growth, social development, and the protection of the ecological environment and explore the dynamic balance between the three to promote the harmony of the whole society must be explored. Development has become an urgent question in the academic and practical fields at this stage and has further reached the national strategic level, thereby becoming an important strategic issue for countries to transform, develop, and adapt to a new environment. In the exploration of many developing countries, China's experience is remarkable, and it has provided other countries with a model for reference. In recent years, China's green innovation efficiency level has moved to the forefront of the former world. Many remarkable achievements have been made; however, many deficiencies exist in the level of environmental protection compared with developed countries, such as Japan, Canada, and the United States. On the one hand, China's green innovation efficiency activities have always been characterized by large quantity, low quality, and policy catering, resulting in the dilemma of low-end locking of green innovation efficiency technologies in the global agricultural modernization level and product industrial chain. On the other hand, the level of environmental protection in most areas of China is not high, and large regional differences are observed, with the south, central, and northeast being in a long-term imbalance and the southeast coast and northeast having a gradual deterioration in environmental protection. At present, these deficiencies in China's environmental protection have a major contribution to the unbalanced and insufficient development of the green innovation efficiency system, which has the functions 
of amplification and acceleration, and its effects also have two sides, namely, improved efficiency and induced risks. Previous studies have also shown that green innovation efficiency has an important impact on the development of the ecological economy (Feng et al. 2018) and is the main way to effectively relieve environmental pressure. In the examination of green innovation efficiency, the role of the ecological environment is critical and even directly affects the trend of environmental protection. The efficiency and green orientations must be followed to avoid the impact of scientific and technological pollution on the environment, and the agricultural economy must be transformed to a green development state with green innovation efficiency (Li 2017). Therefore, the role of green innovation efficiency on environmental protection must be explored in the context of the actual situation of each region in the Yangtze River Economic Zone, and the possible paths of green innovation efficiency on environmental protection must be determined. The vitality of green innovation efficiency must be stimulated and green development of social economy in various regions of the Yangtze River Economic Belt must be promoted to provide theoretical completeness and practical operability for improving ecology.

\section{PAST STUDIES}

Environmental protection can not only promote long-term economic growth but also effectively drive the transformation of regional economic industrial structure to achieve high-quality economic development. Many studies on the mechanism by which to drive environmental protection have been conducted, and the core perspectives of the research are mainly divided into three categories: governmental perspective, environmental perspective, and environmental protection measurement. From the perspective of the government, this concept mainly includes agricultural supply-side structure (Li et al. 2020), agricultural support policy (Ma et al. 2020), industrial structure (Shi et al. 2019), industrial agglomeration (Xue et al. 2019), and land use (Lu et al. 2017). From the environmental perspective, this concept mainly focuses on environmental constraints (Wang et al. 2020), ecological compensation (He 2020), ecological cycle (Peng et al. 2019), and institutional environment. In the measurement of environmental protection, the environmental protection level of Tibet (Zhou 2019), the northeast of central and southern China, Zhejiang (Wei et al. 2018), and other regions is mainly measured. These studies illustrate that this concept must be supported from the aspects of the agricultural supply side, industrial structure, and institutional environment to promote a systematic project of environmental protection and the advancement of environmental protection.
Green innovation efficiency will directly cooperate with environmental regulation to promote the environmental protection level, and the clear water and green mountains are equal to mountains of gold and silver (Duan et al. 2020). A large number of studies have shown that green innovation efficiency has an important impact on the development of the ecological economy and is the main way to effectively relieve environmental pressure. In the examination of green innovation efficiency, the role of the ecological environment is critical and directly affects the trend of environmental protection. The efficiency and green orientations are followed to avoid the impact of scientific and technological pollution on the environment, and the agricultural economy is transformed into a green development state with green innovation efficiency. At present, China's green innovation efficiency level lags behind the comprehensive development level of the ecological environment, especially in the northeast, central, and western regions of China, which are all regions with lagging green innovation efficiency level; This notion shows that the coordinated development level of green innovation efficiency and ecological environment is generally low with large differences between provinces, demonstrating a pattern of high in the east and low in the central and western regions. The efficiency of green innovation is the main driving force to promote the growth of the regional green economy (Wang 2013). The environmental protection level of the Yangtze River Economic Belt, a major developmental strategic region of the country, is related to the overall situation of the national ecological environment health. However, the overall green innovation efficiency level of the Yangtze River Economic Belt is low and relatively stable. This level is high in the east, low in the west and unchanged in the central region because of the limitation in scientific and technological investment and market environment factors. The positive impact of green innovation efficiency in the Yangtze River Economic Belt on ecological environmental efficiency has an obvious threshold effect, showing an inverted U-shaped change trend; however, it has not yet formed a long-term mechanism effect of positive interaction (Yan et al. 2019). The green innovation efficiency and green development index of the Yangtze River Economic Belt are generally rising, but the level is relatively low. The coordination degree of green innovation efficiency and green development in the Yangtze River Delta is higher than those in other regions (Wang et al. 2016).

This paper attempts to explore the impact of green innovation efficiency on environmental protection and clarify what role the ecological environment plays in green innovation efficiency and environmental protection and its internal mechanism, which helps promote the realization of green innovation technology, the improvement of the ecological 
environment, and the development of green agriculture. The marginal contributions of this paper are as follows: First, the environmental protection level of the Yangtze River Economic Belt is measured, and the reasons for the differences are analyzed. Second, the environmental protection level verifies the relationship between green innovation efficiency and environmental protection. Third, the identification test is carried out based on the path of ecological environment mechanism by using the intermediary effect model to clarify the mechanism of green innovation efficiency on environmental protection.

\section{MATERIALS AND METHODS}

\section{Model Design}

Benchmark model construction: A basic regression model is constructed to analyze the impact of green innovation efficiency on environmental protection in the Yangtze River Economic Belt as a whole and in the upper, middle, and lower reaches of the region:

$$
A G D_{i t}=\beta_{0}+\beta_{1} \text { Technology }_{\mathrm{it}}+\sum \text { Control }+\varepsilon_{i t}
$$

Where $i$ means province, $t$ means year, $A G D_{i t}$ is an explanatory variable that indicates environmental protection. Technolog $y_{i t}$ is the core explanatory variable and represents the efficiency of green innovation. $\beta_{0}$ is a constant term. $\Sigma$ Control is a control variable and mainly includes the main factors affecting environmental protection: economic development level, government intervention, openness, urbanization rate, industrial modernization, higher educational level, governmental scale, marketization level, and openness. $\varepsilon_{i t}$ is the interference item.

Construction of the mediation model: This study first separately includes green innovation efficiency into the regression equation to test the mechanism of green innovation efficiency on environmental protection [Formula (2)]. Subsequently, the separate effect of green innovation efficiency on environmental protection is analyzed. Then, the effect of green innovation efficiency on the ecological environment is examined (Formula (3)). Finally, the ecological environment is incorporated into Formula (3), see Formula (4), to judge whether the efficiency of green innovation affects the level of environmental protection through the ecological environment. The specific model is as follows:

$$
\begin{gathered}
A G D_{i t}=\beta_{0}+\beta_{1} \text { Technology }_{\mathrm{it}}+\sum \text { Control }+\varepsilon_{i t} \\
A E E_{i t}=\alpha_{0}+\alpha_{1} \text { Technology }_{\mathrm{it}}+\sum \text { Control }+\varepsilon_{i t} \\
A G D_{i t}=\pi_{0}+\pi_{1} \text { Technology }_{\mathrm{it}}+\pi_{2} \mathrm{AEE}_{\mathrm{it}}+\sum \text { Control }+\varepsilon_{i t} .
\end{gathered}
$$

Where $A E E_{i t}$ represents the ecological environment. $A G D_{i t}$ and $\Sigma C$ Control represent the explained and controlled variables, respectively, and their meanings are the same as those in Formula (1). $\beta_{1}$ reflects the total effect of green innovation efficiency on environmental protection. $\pi_{1}$ reflects the direct effect of green innovation efficiency on environmental protection. $\alpha_{1} \pi_{2}$ reflects the size of the mediation effect. The ratio of the mediation effect to the total effect is used to reflect the relative size of the mediation effect. Sobel statistics can be used to test the significance of the mediation effect.

\section{Variable Setting}

Explained variables: Environmental protection level. This variable involves society, economy, population, resources, ecological environment, and other aspects, and is a comprehensive concept, which mainly describes the response of various factors to the environmental protection level of each province. The DPSIR conceptual model is an evaluation model for measuring the sustainable development of the social environment, which can comprehensively summarize the above-mentioned aspects and accurately describe the relationship between human activities and the ecological environment. This model has the advantages of comprehensiveness, scientific, and systematic and is widely used in ecological resource and environmental impact analysis, water resource security evaluation, regional ecological environment security, and other fields. The DPSIR conceptual model is applied to the index system of environmental protection. The logic can be expressed as follows: The changes of potential factors, such as society, economy, population, resources, and ecological environment, are taken as the driving forces $\mathrm{D}$; pressure is exerted on the ecological environment $\mathrm{P}$; and the ecological environment is changed, causing the state $S$ of the ecological environment to change and affecting the ecological environment I. These influences encourage human beings to respond to the ecological environment $\mathrm{R}$ and take certain measures. These responses $\mathrm{R}$ will affect the pressure $\mathrm{P}$, driving force $\mathrm{D}$, state $\mathrm{S}$, and influence I. Therefore, this study draws lessons from the practices of Liu (2020) to apply the environmental protection evaluation model and entropy method to calculate the weight of each index. Moreover, the comprehensive evaluation method is adopted to weigh and sum the environmental protection indexes of each index to obtain the environmental protection values of each province in the Yangtze River Economic Belt from 2007 to 2017. The environmental protection index system is shown in Table 1.

\section{Core Explanatory Variables}

Green innovation efficiency. In this study, green innovation efficiency is expressed by comprehensive efficiency, which better reflects the relationship between the input and the 
Table 1: Evaluation index system of environmental protection in provinces of Yangtze River Economic Belt.

\begin{tabular}{|c|c|c|c|}
\hline Target Layer & Criteria layer & Indicator layer & \\
\hline \multirow[t]{15}{*}{$\begin{array}{l}\text { Environmental } \\
\text { protection }\end{array}$} & \multirow[t]{3}{*}{$\begin{array}{l}\text { Driving } \\
\text { force (D) }\end{array}$} & Added value of primary industry & $\begin{array}{l}\text { Per capita output value of agriculture, forestry, animal } \\
\text { husbandry and fishery }\end{array}$ \\
\hline & & Per capita income of rural residents & Consumption level of rural residents \\
\hline & & Land output rate & \\
\hline & \multirow{3}{*}{$\begin{array}{l}\text { Pressure } \\
\text { (P) }\end{array}$} & \multicolumn{2}{|c|}{ Use amount of chemical fertilizer, pesticide and agricultural film per unit area } \\
\hline & & \multicolumn{2}{|l|}{ Proportion of disaster area to disaster area } \\
\hline & & \multicolumn{2}{|l|}{ Proportion of effective irrigation area } \\
\hline & \multirow{3}{*}{$\begin{array}{l}\text { Status } \\
(\mathrm{S})\end{array}$} & Agricultural water consumption & Output value of agricultural GDP per unit area \\
\hline & & Grain output per unit area & Water-saving irrigation area \\
\hline & & Road mileage per capita in rural areas & \\
\hline & \multirow{3}{*}{$\begin{array}{l}\text { Impact } \\
\text { (I) }\end{array}$} & Output of green agricultural products & Forest coverage \\
\hline & & Coverage rate of sanitary toilets & Qualified rate \\
\hline & & Wastewater discharge & \\
\hline & \multirow[t]{3}{*}{$\begin{array}{l}\text { Response } \\
\text { (R) }\end{array}$} & $\begin{array}{l}\text { Government Investment in Rural } \\
\text { Water and Toilet Improvement }\end{array}$ & Industrial structure adjustment index \\
\hline & & \multicolumn{2}{|c|}{ Proportion of budget expenditure for energy conservation and protection } \\
\hline & & $\begin{array}{l}\text { Research and experimental } \\
\text { development personnel }\end{array}$ & Proportion of investment in environmental pollution control \\
\hline
\end{tabular}

output of green innovation efficiency. Innovation investment includes capital and manpower investment. This study selects the main investment of scientific and technological research and development, the number of scientific research personnel invested in scientific and technological research and development, and the total financial expenditure on science and technology as input variables. The output includes scientific, technological, economic, and social benefit outputs. This study selects patent level, new variety level, the annual growth rate of added value, the full-time equivalent of $R \& D$ personnel, the total number of published articles, patent authorization amount, invention patent authorization amount, the transaction amount of various technology contracts, profit of high-tech products, and non-governmental expenditure in scientific and technological activity expenditure. This study calculates the comprehensive efficiency value of green innovation efficiency of each province in the Yangtze River Economic Belt from 2007 to 2017.

Ecological environment. In this study, references are made to the ecological efficiency of German environmental and economic accounting account according to the requirements and realistic path of ecological environment development. The input indicators include resource consumption and environmental cost. This study selects human, financial, and material resources engaged in production to express, and environmental cost is expressed by material consumption (mainly including fertilizer, pesticide, agricultural film, and fuel input) that will cause pollution in production input. The

Table 2: Index system of ecological environmental efficiency.

\begin{tabular}{|c|c|c|c|}
\hline \multirow[t]{7}{*}{ Index system } & System layer & \multicolumn{2}{|l|}{ Indicator layer } \\
\hline & Unexpected output & \multicolumn{2}{|l|}{ Carbon emissions $(\mathrm{kg})$} \\
\hline & Expected output & \multicolumn{2}{|c|}{ Total agricultural output value (100 million yuan) } \\
\hline & Input & Manpower input & Number of Agriculture, Forestry, Animal Husbandry and Fishery $(10,000)$ \\
\hline & & Material consumption & $\begin{array}{l}\text { Total sown area of crops (thousands of hectares), total rural electricity consump- } \\
\text { tion (KW.H), effective irrigation area (thousands of hectares), and total power } \\
\text { of agricultural machinery (10,000 kilowatts) }\end{array}$ \\
\hline & & $\begin{array}{l}\text { Consumption of financial } \\
\text { resources }\end{array}$ & Agricultural investment (yuan) \\
\hline & & Environmental cost & $\begin{array}{l}\text { Fertilizer usage ( } 10,000 \text { tons), agricultural film usage ( } 10,000 \text { tons), pesticide } \\
\text { usage }(10,000 \text { tons }) \text { and agricultural diesel usage }(10,000 \text { tons }) \text {. }\end{array}$ \\
\hline
\end{tabular}


output indicators are expressed by gross output value and carbon emissions. An input-output index system for evaluating ecological environmental efficiency is constructed to measure ecological environmental efficiency by using the non-radial super-efficiency EBM model proposed by Tone (2010) as a reference (Table 2).

Control variables: Based on previous research results, this study takes economic development level, government intervention degree, openness degree, urbanization rate, industrial modernization degree, higher education level, government scale, marketization degree, and opening level as control variables. The level of economic development is expressed by the actual GDP per capita. The degree of government intervention is expressed by general budget expenditure/ GDP. The degree of industrial modernization is expressed by tertiary GDP/primary GDP. The level of higher education is expressed by the number of graduates from junior college or above. The scale of government is expressed by governmental consumption expenditure/GDP. The level of opening to the outside world is expressed by FDI/GDP. The degree of opening to the outside world is expressed by import and export/GDP.

\section{Data Sources}

According to the availability and integrity of data, this study selects 11 provinces (cities) belonging to the Yangtze River Economic Belt from 2007 to 2017 as the research objects. According to the national administrative division standard, the Yangtze River Economic Belt as a whole and the upper, middle, and lower reaches are divided. The upper reaches include Chongqing, Sichuan, Yunnan, and Guizhou, the middle reaches consist of Jiangxi, Hunan, and Hubei, and the lower reaches comprised Jiangsu, Shanghai, Zhejiang, and Anhui. All the data come from the provincial statistical yearbooks, science and technology statistical yearbooks, and the official website of the National Bureau of Statistics.

\section{RESULTS ANALYSIS}

\section{Differences in Environmental Protection Levels in the Yangtze River Economic Belt and Their Causes}

The following trend analysis is conducted to reveal the differences and causes of environmental protection levels in the three regions of the Yangtze River Economic Belt. Fig. 1 reflects the differences and evolution trends of environmental protection levels in the overall, upper, middle, and lower regions of the Yangtze River Economic Belt.

From the regional level, the environmental protection level in the upper reaches is the highest, followed by the lower and middle reaches. The environmental protection level in the upper reaches is greater than the overall level of the Yangtze River Economic Belt. Meanwhile, the environmental protection level in the lower and middle reaches is lower than the overall level of the Yangtze River Economic Belt. The possible reason is that the upstream areas are located in the western region of China. Although the economic level is low, the region has natural ecological advantages. The clear water and green are equal to mountains of gold and silver because the region is the ecological barrier area in China, highlighting the remarkable green ecological economy; thus, the environmental protection level is the highest. The lower reaches of the Yangtze River are located in the eastern region of China, with coastal location advantages and rapid economic development, attracting international advanced technology and first-class talents and taking the lead in realizing the transformation of economic development mode to green, ecological, and high-quality development through rapid human capital and material capital. Hence, the level of environmental protection takes second place. The middle reaches region is located in the central part of China. With the policy of the rise of the central region and its proximity to the lower reaches region, the area became the first choice for the transfer of pollution-intensive industries in the lower reaches region, virtually prompting the middle reaches region to exchange economic growth at the expense of the environment. This situation resulted in a rough industrial structural dependence path. Accordingly, the environmental protection level is the lowest.

\section{Impact of Green Innovation Efficiency in the Yangtze River Economic Belt on Environmental Protection}

The previous part reveals the regional differences and causes of environmental protection levels in the Yangtze River Economic Belt and various regions. This study aims to further explore the influencing factors of environmental

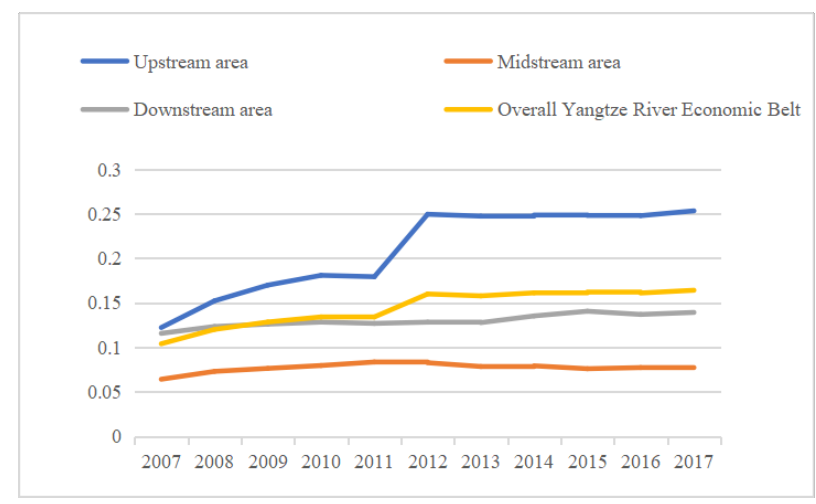

Fig. 1: Changes in the environmental protection level in the Yangtze River Economic Belt. 
Table 3: Regression results of the impact of green innovation efficiency on environmental protection in the Yangtze River Economic Belt and the upper, middle, and lower reaches.

\begin{tabular}{|c|c|c|c|c|}
\hline & Yangtze River Economic Belt & Downstream area & Midstream region & Upstream region \\
\hline & (1) & (2) & (3) & (4) \\
\hline & Environmental protection & Environmental protection & Environmental protection & Environmental protection \\
\hline \multirow{2}{*}{$\begin{array}{l}\text { Green innovation } \\
\text { efficiency }\end{array}$} & $0.00103 * *$ & $-0.0138 * *$ & 0.00188 & $0.131 * * *$ \\
\hline & $(0.07)$ & $(-2.28)$ & $(0.38)$ & $(4.33)$ \\
\hline \multirow{2}{*}{$\begin{array}{l}\text { Economic development } \\
\text { level }\end{array}$} & $0.187 * * *$ & $0.0963 * * *$ & 0.00437 & -0.133 \\
\hline & $(2.90)$ & $(4.38)$ & $(0.25)$ & $(-1.14)$ \\
\hline \multirow{2}{*}{$\begin{array}{l}\text { Degree of government } \\
\text { intervention }\end{array}$} & 0.000990 & 0.000636 & $-0.000906^{*}$ & $-0.00730 * * *$ \\
\hline & $(0.57)$ & $(0.67)$ & $(-1.72)$ & $(-3.56)$ \\
\hline \multirow[t]{2}{*}{ Openness } & $0.00278 * * *$ & 0.0000803 & 0.000525 & $0.00570 * * *$ \\
\hline & $(6.95)$ & $(0.51)$ & $(1.35)$ & $(3.80)$ \\
\hline \multirow[t]{2}{*}{ Urbanization rate } & $-0.0124 * * *$ & 0.000434 & -0.0000591 & $-0.0103 * *$ \\
\hline & $(-4.06)$ & $(0.58)$ & $(-0.07)$ & $(-1.97)$ \\
\hline \multirow{2}{*}{$\begin{array}{l}\text { Degree of industrial } \\
\text { modernization }\end{array}$} & -0.0000679 & $0.000201 * *$ & $0.00751 * *$ & 0.0265 \\
\hline & $(-0.17)$ & $(2.01)$ & $(2.40)$ & $(1.50)$ \\
\hline \multirow[t]{2}{*}{ Higher education level } & $0.00246 * *$ & $0.00223 * * *$ & -0.000285 & 0.00436 \\
\hline & $(1.26)$ & $(-7.72)$ & $(-1.00)$ & $(0.89)$ \\
\hline \multirow[t]{2}{*}{ Government size } & -0.00442 & 0.000418 & -0.000394 & $-0.0343 * * *$ \\
\hline & $(-1.35)$ & $(0.29)$ & $(-0.64)$ & $(-8.72)$ \\
\hline \multirow[t]{2}{*}{ Marketization degree } & 0.000877 & $0.00112 * *$ & -0.0000308 & -0.00304 \\
\hline & $(0.66)$ & $(2.10)$ & $(-0.06)$ & $(-0.84)$ \\
\hline \multirow{2}{*}{$\begin{array}{l}\text { Level of opening to the } \\
\text { outside world }\end{array}$} & $-0.0293 * * *$ & $-0.00382 *$ & $-0.0138 * * *$ & $-0.0346^{* * *}$ \\
\hline & $(-6.08)$ & $(-1.84)$ & $(-4.42)$ & $(-2.67)$ \\
\hline \multirow[t]{2}{*}{ Constant term } & $-1.306^{* *}$ & $-0.827 * * *$ & 0.0834 & $1.847 * *$ \\
\hline & $(-2.54)$ & $(-4.46)$ & $(0.58)$ & $(2.25)$ \\
\hline $\mathrm{N}$ & 121 & 44 & 33 & 44 \\
\hline
\end{tabular}

Note: *, ** and *** represent $\mathrm{P}<0.1, \mathrm{P}<0.05$ and $\mathrm{P}<0.01$, respectively

protection levels in the Yangtze River Economic Belt and various regions. A reasonable explanation for the regional differences affecting the environmental protection level of the Yangtze River Economic Belt can be obtained by analyzing the changes of the coefficients of various influencing factors in different regions of the Yangtze River Economic Belt from 2007 to 2017. Accordingly, the coordinated improvement of the environmental protection level in the development process of the Yangtze River Economic Belt is advanced. Table 3 lists the regression results of the impact of green innovation efficiency on the environmental protection level in the Yangtze River Economic Belt as a whole and various regions.

Column (1) in Table 3 reports the regression results of the impact of green innovation efficiency on the overall environmental protection of the Yangtze River Economic
Belt. The results show that the coefficient of green innovation efficiency is considerably positive at the $5 \%$ level. This result indicates that the green innovation efficiency of the Yangtze River Economic Belt has promoted environmental protection. The possible reason is that the green innovation efficiency can promote the economic growth of the Yangtze River Economic Belt in the face of environmental constraints and improve the environmental quality and environmental protection level. The coefficient of economic development level is significantly positive at the $1 \%$ level. This notion shows that the economic development level of the Yangtze River Economic Belt has promoted environmental protection. The possible reason is that the economic development level is better, which can gather more high-level human capital and attract more high-green innovation efficiency enterprises, and the government's environmental protection supervision will 
be stronger, thereby effectively improving the environmental protection level. The openness coefficient is considerably positive at the $5 \%$ level. This result shows that the improvement of the openness of the Yangtze River Economic Belt has promoted the environmental protection level. The possible reason is that the improvement of openness can attract more high-tech enterprises, eliminate local backward production enterprises, introduce environment-friendly scientific and technological equipment and advanced technology level, save energy, and reduce emissions. This situation is conducive to the improvement of environmental protection level. The coefficient of higher educational level is drastically positive at the 5\% level, which indicates that the improvement of educational level in the Yangtze River Economic Belt can promote the environmental protection level. The possible reason is that the improvement of educational level can increase people's awareness and behavior of environmental protection and promote the environmental protection level.

\section{Analysis of the Differences Among the Lower, Middle and Upper Reaches}

Columns (2), (3) and (4) in Table 3 are the comparison of the impact of green innovation efficiency on environmental protection in the lower, middle, and upper reaches of the Yangtze River. Column (2) results show that the coefficient of green innovation efficiency is negative at the 5\% level. This result shows that the efficiency of green innovation has a meaningful inhibitory effect on the environmental protection level in the downstream areas. The possible reason is that the proportion of secondary industry in the downstream areas continues to rise. Industrial pollution is one of the main sources of ecological environment pollution. Excessive industrial pollution aggravates the pollution of the ecological environment, resulting in a lower level of environmental protection in the downstream areas. Column (3) results show that the coefficient of green innovation efficiency is not significantly positive. This notion shows that the efficiency of green innovation has no obvious promotion effect on the environmental protection level in the middle reaches. The logic behind this may be that the middle reaches are close to the lower reaches and are the first choice for the transfer of pollution-intensive industries in the eastern region, such as paper industry, chemical industry, building materials industry, and other industries, which have degraded the ecological environment in the middle reaches. Column (4) results show that the coefficient of green innovation efficiency is clear positive at the $1 \%$ level. This notion shows that the efficiency of green innovation can promote the environmental protection level in upstream areas. The upstream area is typical mountain agriculture with inconvenient transportation, less industrial transfer in the east, and a relatively high proportion of primary industry. In addition, this area is China's ecological barrier and functional area, and the environmental protection level is better. Therefore, the environmental protection level is promoted.

\section{Mechanism of Green Innovation Efficiency on Environmental Protection}

The coefficient of green innovation efficiency in column (1) of Table 4 is positively at the $1 \%$ level, thus indicating that green innovation efficiency has greatly enhanced the improvement of ecological environmental efficiency. Green innovation efficiency promotes technological progress, brings advanced technological level to economic development, and realizes modernization level, thus promoting the improvement of ecological environmental efficiency. The coefficient of green innovation efficiency in column (2) is significantly positive at the $1 \%$ level, which indicates that green innovation efficiency is very effective in accelerating the improvement of environmental protection level. Green innovation efficiency promotes environmental protection by improving production methods, increasing land output efficiency, reducing rural environmental pollution, promoting green, organic, and high-quality agricultural products, completing the rural toilet revolution, and increasing forest and grass coverage. Column (3) shows that the ecological environmental coefficient is considerably positive at the $1 \%$ level, which indicates that the improvement of ecological environmental efficiency significantly promotes the level of environmental protection. The coefficient of green innovation efficiency is appreciably positive at the $10 \%$ level. The comparison of the green innovation efficiency coefficients in column (2) indicated that the variable coefficient of green innovation efficiency is smaller (from 0.127 to 0.0758 ) after ecological environmental efficiency variables are added to column (3). The significance also decreased by a noticeable percentage (from $1 \%$ to $10 \%$ ), that is, the promotion of green innovation efficiency to environmental protection weakened with the addition of ecological environmental efficiency variables. This notion indicates that ecological environmental efficiency plays an important intermediary effect between green innovation efficiency and environmental protection. Accordingly, a positive transmission path of "green innovation efficiency (improving) ecological environmental efficiency (promoting) environmental protection level" has been formed.

\section{CONCLUSION}

Based on the panel data of provinces and cities in the Yangtze River Economic Belt from 2007 to 2017, this study analyzes the change trend and causes of environmental protection 
Table 4: Transmission mechanism of green innovation efficiency to environmental protection in Yangtze River Economic Belt

\begin{tabular}{|c|c|c|c|c|c|c|}
\hline & \multicolumn{3}{|c|}{ Yangtze River Economic Belt } & \multicolumn{3}{|c|}{ Upstream region } \\
\hline & (1) & (2) & (3) & (4) & (5) & (6) \\
\hline & $\begin{array}{l}\text { Ecological } \\
\text { efficiency }\end{array}$ & $\begin{array}{l}\text { Environmental } \\
\text { protection }\end{array}$ & $\begin{array}{l}\text { Environmental } \\
\text { protection }\end{array}$ & $\begin{array}{l}\text { Ecological } \\
\text { efficiency }\end{array}$ & $\begin{array}{l}\text { Environmental } \\
\text { protection }\end{array}$ & $\begin{array}{l}\text { Environmental } \\
\text { protection }\end{array}$ \\
\hline \multirow{2}{*}{$\begin{array}{l}\text { Ecological environment } \\
\text { efficiency }\end{array}$} & & & $0.324 * * *$ & & & $0.198 * *$ \\
\hline & & & $(2.90)$ & & & $(2.49)$ \\
\hline \multirow{2}{*}{$\begin{array}{l}\text { Green innovation } \\
\text { efficiency }\end{array}$} & $0.159 * * *$ & $0.127 * * *$ & $0.0758^{*}$ & $0.210 * * *$ & $0.196 * * *$ & $0.154 * * *$ \\
\hline & $(5.11)$ & $(3.36)$ & $(1.87)$ & $(3.06)$ & $(5.09)$ & $(3.90)$ \\
\hline \multirow{2}{*}{$\begin{array}{l}\text { Economic development } \\
\text { level }\end{array}$} & $0.189 *$ & $-0.660 * * *$ & $-0.736 * * *$ & -0.0571 & $-0.151 *$ & $-0.140 *$ \\
\hline & $(1.70)$ & $(-4.67)$ & $(-5.19)$ & $(-0.36)$ & $(-1.71)$ & $(-1.69)$ \\
\hline \multirow{2}{*}{$\begin{array}{l}\text { Degree of government } \\
\text { intervention }\end{array}$} & $-0.00771 *$ & -0.00597 & -0.00334 & $0.0178 * * *$ & 0.00315 & -0.000365 \\
\hline & $(-1.85)$ & $(-1.35)$ & $(-0.72)$ & $(2.85)$ & $(0.90)$ & $(-0.10)$ \\
\hline \multirow[t]{2}{*}{ Openness } & $-0.00344 * * *$ & $-0.00448 * * *$ & $-0.00343 * * *$ & -0.00556 & -0.00129 & -0.000195 \\
\hline & $(-4.59)$ & $(-4.74)$ & $(-3.46)$ & $(-1.47)$ & $(-0.61)$ & $(-0.10)$ \\
\hline \multirow[t]{2}{*}{ Urbanization rate } & $0.0151 * *$ & $0.0508 * * *$ & $0.0463 * * *$ & -0.00751 & 0.000844 & 0.00233 \\
\hline & $(2.26)$ & $(6.46)$ & $(5.88)$ & $(-0.77)$ & $(0.15)$ & $(0.45)$ \\
\hline \multirow{2}{*}{$\begin{array}{l}\text { Degree of industrial } \\
\text { modernization }\end{array}$} & $-0.00210 * *$ & 0.000175 & 0.000834 & $-0.148 * * *$ & $-0.131 * * *$ & $-0.102 * * *$ \\
\hline & $(-2.53)$ & $(0.19)$ & $(0.86)$ & $(-2.78)$ & $(-4.36)$ & $(-3.34)$ \\
\hline \multirow[t]{2}{*}{ Higher education level } & 0.00574 & 0.00482 & 0.00335 & $0.0313 * *$ & $0.0179 * *$ & 0.0117 \\
\hline & $(1.51)$ & $(0.98)$ & $(0.70)$ & $(2.31)$ & $(2.35)$ & $(1.55)$ \\
\hline \multirow[t]{2}{*}{ Government size } & $-0.0119 *$ & $-0.0241 * * *$ & $-0.0207 * * *$ & $-0.0271 * * *$ & $-0.0270 * * *$ & $-0.0216 * * *$ \\
\hline & $(-1.95)$ & $(-3.10)$ & $(-2.75)$ & $(-2.89)$ & $(-5.13)$ & $(-4.03)$ \\
\hline \multirow[t]{2}{*}{ Marketization degree } & 0.0000800 & $-0.0109 * * *$ & $-0.0110 * * *$ & $0.0261 * *$ & 0.00714 & 0.00198 \\
\hline & $(0.03)$ & $(-3.35)$ & $(-3.54)$ & $(2.55)$ & $(1.24)$ & $(0.34)$ \\
\hline \multirow{2}{*}{$\begin{array}{l}\text { Level of opening to the } \\
\text { outside world }\end{array}$} & -0.0100 & $-0.0309 * * *$ & $-0.0271 * *$ & 0.00678 & 0.00181 & 0.000467 \\
\hline & $(-1.07)$ & $(-2.61)$ & $(-2.38)$ & $(0.19)$ & $(0.09)$ & $(0.02)$ \\
\hline \multirow[t]{2}{*}{ Constant term } & $-2.041 * *$ & $5.890 * * *$ & $6.682 * * *$ & -0.247 & $1.610 * *$ & $1.658 * *$ \\
\hline & $(-2.28)$ & $(5.10)$ & $(5.73)$ & $(-0.19)$ & $(2.24)$ & $(2.46)$ \\
\hline $\mathrm{N}$ & 121 & 121 & 121 & 44 & 44 & 44 \\
\hline
\end{tabular}

Note: *,**,*** represent $\mathrm{P}<0.1, \mathrm{P}<0.05, \mathrm{P}<0.01$ respectively

level and empirically tests the impact and mechanism of green innovation efficiency on environmental protection. Moreover, this study conducts robustness tests and proposes relevant policy implications.

The main conclusions are as follows. The overall environmental protection level of the Yangtze River Economic Belt is on the rise, with the highest level of environmental protection in the upper reaches, the second in the lower reaches, and the lowest in the middle reaches. Green innovation efficiency promotes the overall environmental protection level of the Yangtze River Economic Belt, inhibits the environmental protection level of the downstream areas, promotes the environmental protection level of the upstream areas, and has no obvious impact on the environmental protection level of the middle reaches. The analysis of the impact mechanism shows that green innovation efficiency can improve the level of environmental protection through ecological environmental efficiency.

This study has the following policy implications. From the perspective of green innovation efficiency level, green innovation efficiency is not conducive to the improvement of environmental protection level in downstream areas, which shows that the input-output performance of green innovation efficiency in downstream areas is low, and 
the growth rate of green innovation efficiency is less than that of the environmental protection level. Therefore, the government should improve the efficiency level of green innovation in downstream areas and focus on improving the output rate of science and technology to ensure that the growth rate of green innovation efficiency exceeds the level of environmental protection. Although China's environmental protection level is on the rise, the overall level is still not high. The economic benefits of green development in agriculture and rural areas are low, the farmers' ideology is not in place, and subsidies for green development are not matched. Therefore, a cooperative promotion mechanism must be established between townships and counties, agricultural superior resources must be integrated and ecological environment, product innovation, and economic benefits must be considered. Moreover, financial support in promoting environmental protection with green innovation efficiency, and green innovation efficiency and environmental protection must be jointly promoted.

\section{ACKNOWLEDGEMENT}

This study was supported by State Forestry Administration Research on major forestry issues (ecological safety) in 2014 (ZDWT201415); The Joint Fund Project of Guizhou University of Finance and Economics and the Research Institute of International Trade and Economic Cooperation of the Ministry of Commerce "Study on the Influencing Factors of Carbon Emission and Total Factor Energy Efficiency in Ecological Fragile Areas" (2017SWBZD13) and The Mining Growth Opportunities from Customer Experience: A Deep Case Study (2020HXZXJGXY003).

\section{REFERENCES}

Duan, X., Dai, S.L. and Liao, K.C. 2020. Research on the coupling and coordination and influencing factors of industrial enterprise ecoefficiency and green innovation efficiency. Science and Technology Management Research, 1: 89-100.

Feng, Y.J., Qi, Q. and Han, J.B. 2018. Spatiotemporal evolution and driving factors of China's agricultural ecological efficiency. Bulletin of Soil and Water Conservation, 12: 254-262.
He, S.K. 2019. Research on the dynamic mechanism and policy of collaborative promotion of rural ecological environment compensation and green development. Modern Economic Research, 6: 106-113.

Li, S. 2017. Green innovation efficiency drives the transformation of agricultural economic development mode. Agricultural Economics. 4: $20-21$

Li, X.W. and Xu, S.B. 2020. The measurement and spatial characteristics of the imbalance of China's agricultural supply structure. Journal of Guangxi University of Finance and Economics, 4: 87-102.

Liu, Z. 2020. Correlation analysis of China's provincial environmental protection index. Statistics and Decision, 7: 91-95

Lu, W.M., Zhang, T.F. and Jiang, Q.J. 2017. Promoting urban green development through the transformation of land use mode: exploration and practice in Shanghai. Environmental Protection, 4: 59-64.

Ma, H.K. and Mao, S.P. 2020. Research on the green ecological transformation of agricultural support policies-based on the comparative analysis of China, Japan and Korea. Economic System Reform, 2: 157-165.

Peng, S. and Wang, Y.H. 2019. Boosting green development with ecological recycling agriculture: Taking Hunan as an example. Journal of Hunan University (Social Science Edition), 3: 1-7.

Shi, Z.H., Mu, H.J. and Sun, Y. 2019. Research on the impact of agricultural subsidies on farmers' participation in environmental protection. Economic Review, 3: 144-154.

Tone, K. and Tsutsui, M. 2010. Dynamic DEA: A Slacks-Based Measure Approach. Omega, 38(3): 145-156.

Wang, B.Y. and Zhang, W.M. 2018. Inter-provincial differences and influencing factors of agricultural ecological efficiency in China: based on panel data analysis of 31 provinces from 1996 to 2015 . Rural China Economics, 1: 46-62.

Wang, Q. 2013. Research on the contribution of agricultural green innovation efficiency to agricultural economic growth based on Solow residual value-taking Hubei province as an example. Agricultural Economics, 6: 6-9.

Wang, Y.Q. and Wan, W.T. 2020. Regional environmental regulation decision-making model guided by green development. System Engineering, 1: 14-15.

Wei, Q., Zhang, B. and Jin, S.Q. 2018. China environmental protection index construction and regional comparative research. Issues of Agricultural Economy, 11: 11-20.

Xue, L., Xu, C.H. and Shen, Y. 2019. Agglomeration of agricultural industry and environmental protection: coupling degree and synergistic effect. Economic Statistics and Decision, 17: 125-129.

Yan, X. and Chang, C. 2019. Research on the dynamic response between green innovation efficiency and ecological environment in the Yangtze River Economic Belt. Journal of Nantong University (Social Science Edition), 5: 22-25.

Zhou, L. 2019. Research on Tibet's environmental protection under the background of rural revitalization. Northwestern Ethnic Studies, 3: 116-127. 